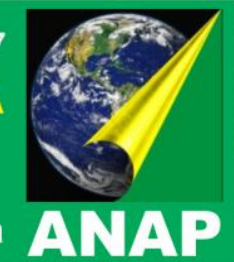

\title{
ANÁLISE MICROCLIMATICA EM DIFERENTES UNIDADES DE PAISAGENS NO PASSO DO LONTRA, PANTANAL DO MIRANDA-MS
}

\author{
Heloissa Gabriela Silva Sokolowski¹ \\ Andressa Gouveia Ponso² \\ Cesar Cardoso Ferreira ${ }^{3}$
}

Arnaldo Yoso Sakamoto ${ }^{4}$

RESUMO: O objetivo geral da pesquisa foi o de contribuir para o conhecimento de microclimas em diferentes paisagens no Pantanal/MS, em especial no Passo do Lontra no Pantanal do Miranda. O procedimento adotado foi baseado na coleta de registros de medidas de temperatura pontual em seis diferentes unidades de paisagens da área de estudada, no intervalo de duração de $1 \mathrm{~h}$ em uma transeção, delimitada em uma rota definida em função da influência da luminosidade solar no decorrer do dia, onde foram coletadas medidas de temperatura em diferentes unidades de paisagens e intervalos do dia: as 9h, $15 \mathrm{~h}$ e as $21 \mathrm{~h}$. Foi realizado um levantamento foto-descritivo dessas unidades, com auxilio de GPS e maquina fotográfica digital. Nas três medidas do transeto, as temperaturas intermediárias foram nos mesmos pontos $(2,3,5$ e 6) as mesmas apresentaram características semelhantes tais como, área construída, arborização, gramínea e solo exposto. Nos pontos 1 e 4 as diferenças de temperatura foram mais acentuadas, combinadas com arborização densa no ponto 1 e solo exposto no ponto 4 . 0 método aplicado revelou-se importante e eficaz para um estudo preliminar da variação micro-climática, nas proximidades da área do Passo do Lontra/MS.

Palavras-chave: Pantanal, paisagem, micro-clima.

\footnotetext{
${ }^{1}$ Acadêmica do curso de Geografia Licenciatura da Universidade federal de Mato Grosso do Sul - heloissa.gss@hotmail.com

${ }_{2}$ Acadêmica do curso de Geografia Licenciatura da Universidade federal de Mato Grosso do Sul - andressa_62@hotmail.com

3 Professor do curso de Geografia da Universidade Federal de Mato Grosso do Sul - cesar_ufms_cptl@yahoo.com.br

${ }^{4}$ Professor do curso de Geografia da Universidade Federal de Mato Grosso do Sul - arnaldosakamoto@gmail.com.
} 


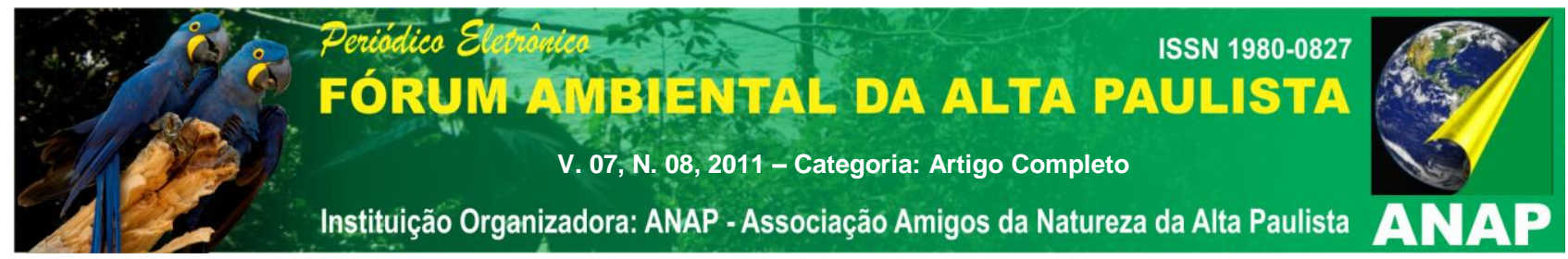

\section{INTRODUÇÃO}

O Pantanal foi subdividido por Silva \& Abdon (1998) em onze regiões conforme a geomorfologia, pedologia e vegetação (Miranda, Paiaguás, Nhecolândia, Abobral, Poconé, Aquidauana, Barão de Melgaço, Cáceres, Nabileque, Paraguai e Porto Murtinho) (Figura 1). O Pantanal Mato-grossense encontra-se na porção central da América do Sul, na Bacia do Alto Paraguai entre as coordenadas $14^{\circ}$ e $22^{\circ}$ de latitude $S$, e $53^{\circ}$ e $59^{\circ}$ de longitude W, compreendendo uma área de $140.000 \mathrm{Km}^{2}$, composta por extensa superfície de acumulação sujeita a inundações periódicas (ALVARENGA et al; 1982; GODOI FILHO 1986; SAKAMOTO et al; 1996; SILVA 2007).

A área estudada é denominada como Passo do Lontra, localizada no Pantanal do Miranda, limitado ao norte pelo Pantanal do Abobral e Nhecolândia, ao sul pelo Pantanal Porto Murtinho, a leste pelo Pantanal de Aquidauana e a oeste pelo Pantanal do Nabileque (Figura 1).

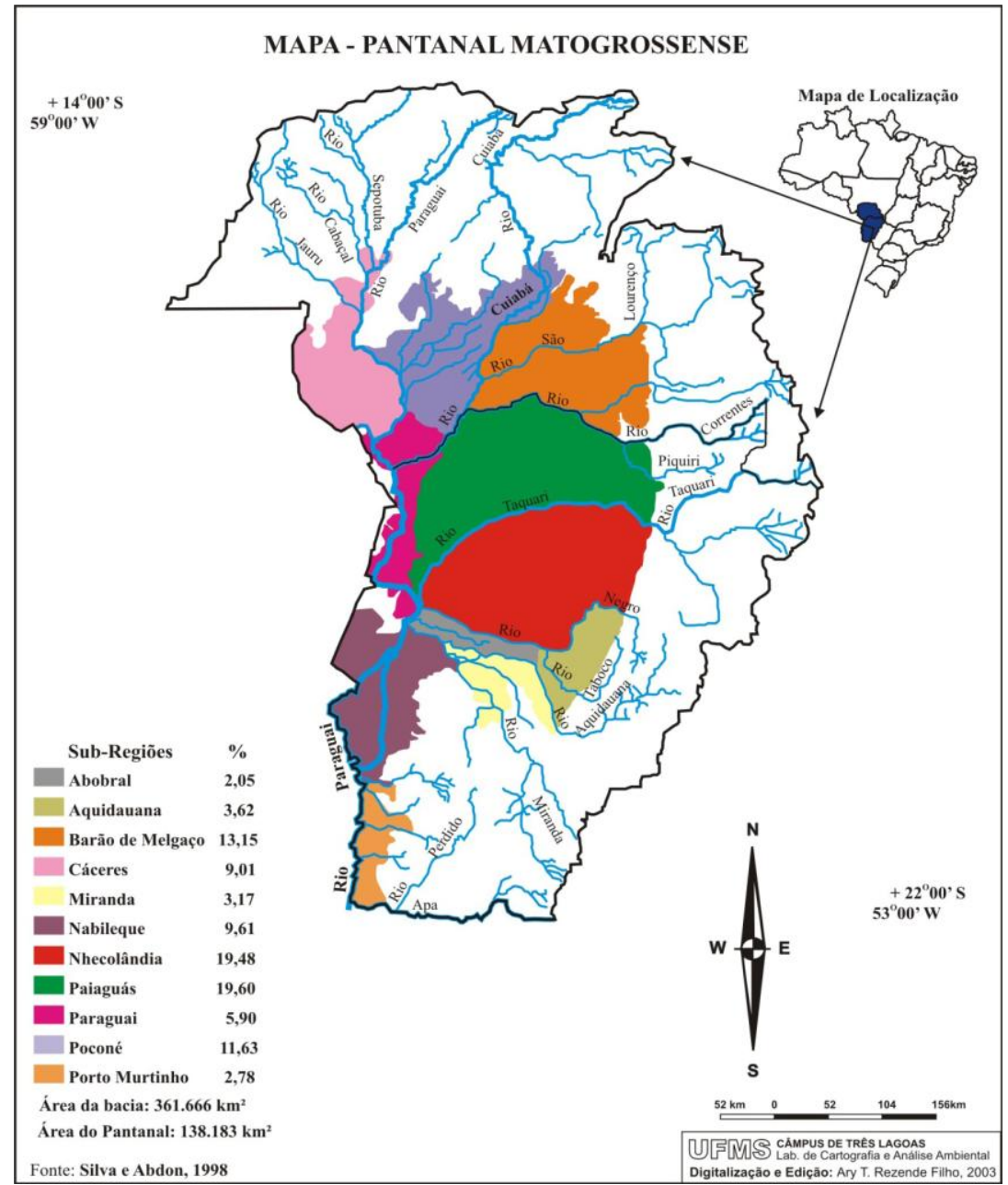




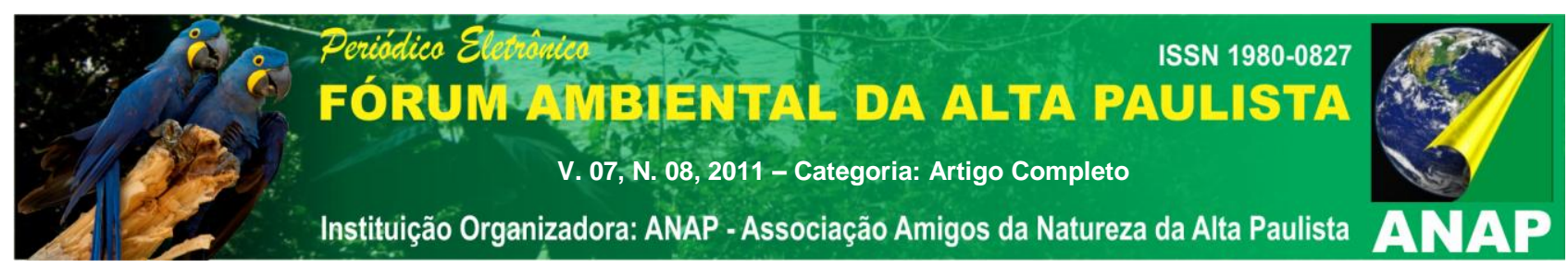

Figura 1 - Sub-regiões do Pantanal Brasileiro, Silva \& Abdon (1998) Org.: REZENDE-FILHO, 2003.

A depressão pantaneira é caracterizada por enchentes anuais periódicas ocasionadas pela baixa declividade regional, sendo o Rio Paraguai o nível de base regional. O clima é do tipo tropical, com duas estações bem definidas, uma seca no inverno e outra chuvosa no verão, com média pluviométrica de 1.100 a $1.800 \mathrm{~mm}$ no planalto e de 850 a $1.100 \mathrm{~mm}$ na depressão com temperatura média de $25^{\circ} \mathrm{C}$ a $26^{\circ} \mathrm{C}$ (ALVARENGA et al; 1982 in GRADELLA et al; 2005).

Este estudo tem como objetivo geral contribuir para o conhecimento de microclimas em diferentes unidades de paisagens no Passo do Lontra. Os objetivos específicos foram: (1) entender as diferentes temperaturas em uma área do Passo do Lontra. (2) analisar os fatores que propiciam o micro-clima desta área, e (3) estudar a influência do uso e ocupação do solo no micro-clima local.

\section{MATERIAIS E MÉTODOS}

O procedimento adotado foi baseado na coleta de registros de medidas de temperatura pontual em seis diferentes unidades de paisagens da área de estudada, no intervalo de duração de $1 \mathrm{~h}$ em uma transeção, delimitada em uma rota definida em função das características das unidades diferenciadas da paisagem e da influência da luminosidade solar no decorrer do dia (Figura 2). 

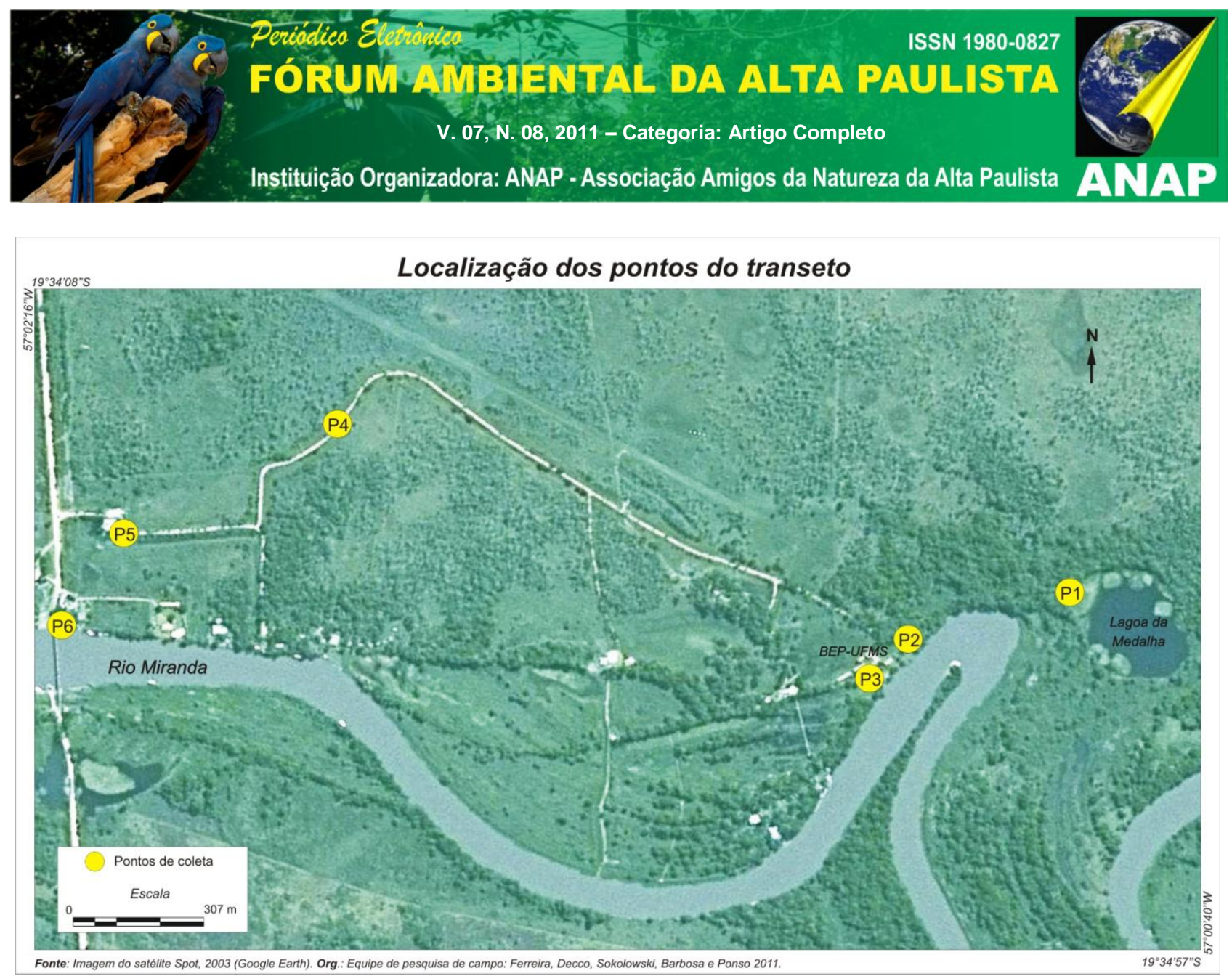

Figura 2: Pontos de registro de medida de temperatura. Org.: FERREIRA.

Os registros das medidas foram realizados no dia 4 de junho de 2011 em diferentes intervalos: das $9 \mathrm{~h}$ ás $10 \mathrm{~h}$, das $15 \mathrm{~h}$ ás $16 \mathrm{~h}$ e das $21 \mathrm{~h}$ até ás $22 \mathrm{~h}$ em condições de tempo anticiclônicas (céu claro) em seis unidades de paisagens: Mata densa próxima a Lagoa da Medalha (P1), mata rala e gramínea á margem direita do Rio Miranda (P2), na área construída da BEP-UFMS (Base de Estudos do Pantanal da Universidade Federal de Mato Grosso do Sul) (P3), na estrada de ligação a BEP-UFMS (P4), na Pousada Passo do Lontra (P5) e na margem direita do Rio Miranda nas proximidades de moradias da comunidade ribeirinha (P6).

Foi realizado um levantamento foto-descritivo para caracterização dessas unidades da paisagem. A orientação do transeto foi de leste para oeste e os dados registrados foram analisados e organizados em gabinete em forma de gráficos e tabelas para a representação dos dados coletados. Outro procedimento realizado em gabinete foram as analises nas imagens do satélite GOES 12 para observação identificação de fenômenos meteorológicos.

Foram utilizados nesse trabalho os seguintes materiais: GPS de navegação Garmim, maquina fotográfica digital, termômetro digital Data Logger no interior do abrigo 


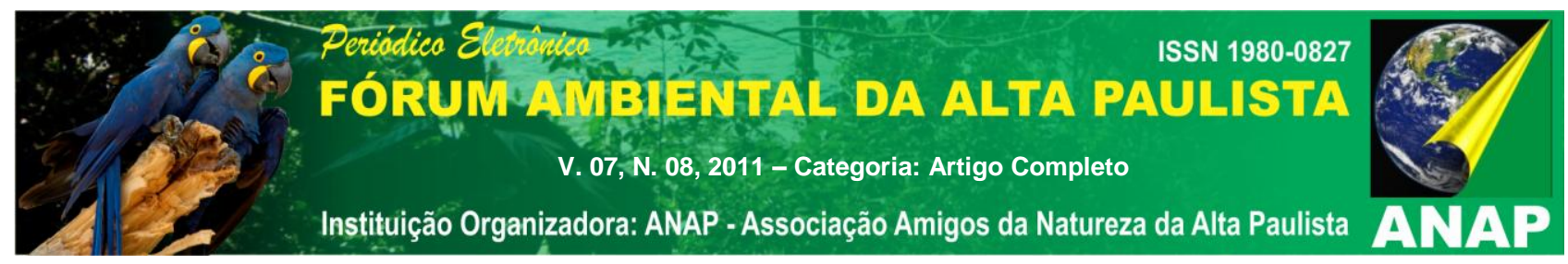

experimental e imagens orbitais do satélite GOES 12 (Infravermelho) dos dias 3 e 4 de junho de 2011.

\section{RESULTADOS}

\subsection{Descrições das paisagens}

As paisagens no pantanal são caracterizadas pela combinação da dinâmica dos elementos físicos, biológicos e antrópicas. De acordo com Bertrand (1973),

A paisagem não é a simples adição de elementos geográficos disparatados. É uma determinada porção do espaço, o resultado da combinação dinâmica, portanto instável, de elementos físicos, biológicos e antrópicas que, reagindo dialèticamente uns sobre os outros, fazem da paisagem um conjunto único e indissociável, em perpetua evolução.

A descrição das paisagens nos pontos do transeto foram realizadas por meio dos levantamentos fotos-descritivos in loco.

O ponto 1 (P1) é caracterizado como um local que apresenta cobertura vegetal densa, o registro foi realizado na margem da lagoa denominada Lagoa da Medalha. Esse ambiente é caracterizado por apresentar uma área de vegetação densa significativa e conseqüentemente com deposição de matéria orgânica no solo, fator importante como elemento de conservação da umidade, mantendo-a relativamente alta. O local abriga indivíduos vegetais de grande e médio porte, porém a abertura entre as copas das árvores permite insolação em diferentes horários do dia (Fotos 1 e 2).

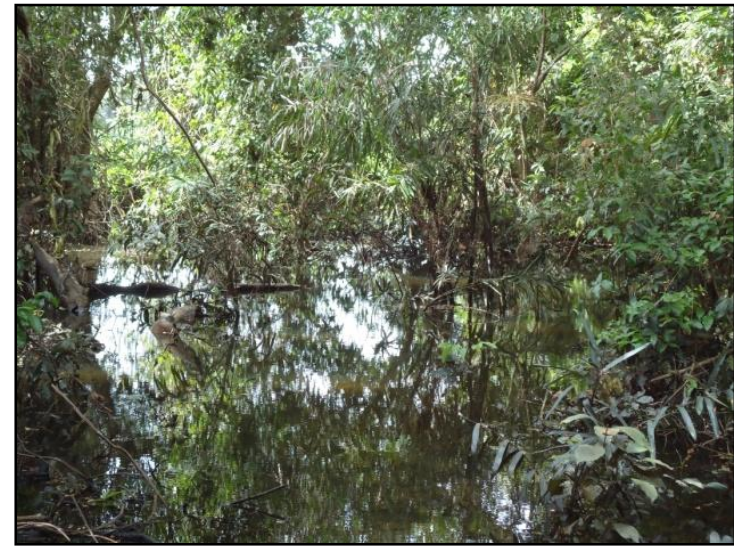

Foto 1: Vegetação próxima a lagoa

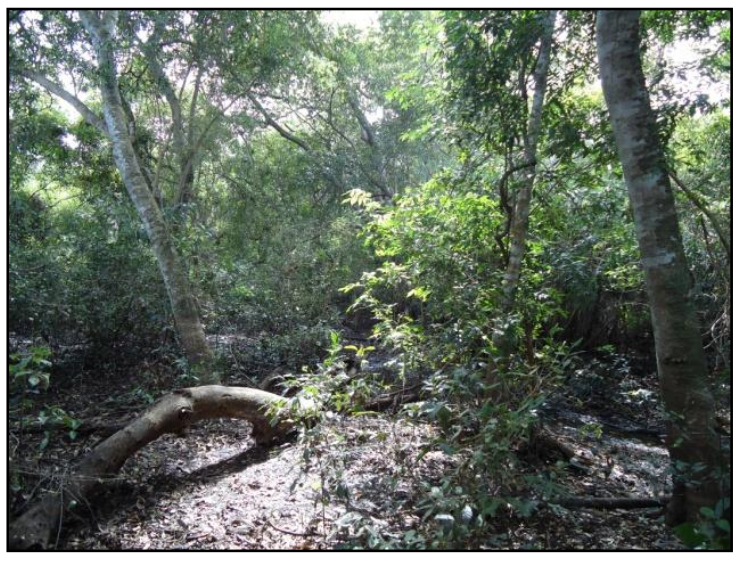

Foto 2: Vegetação densa 


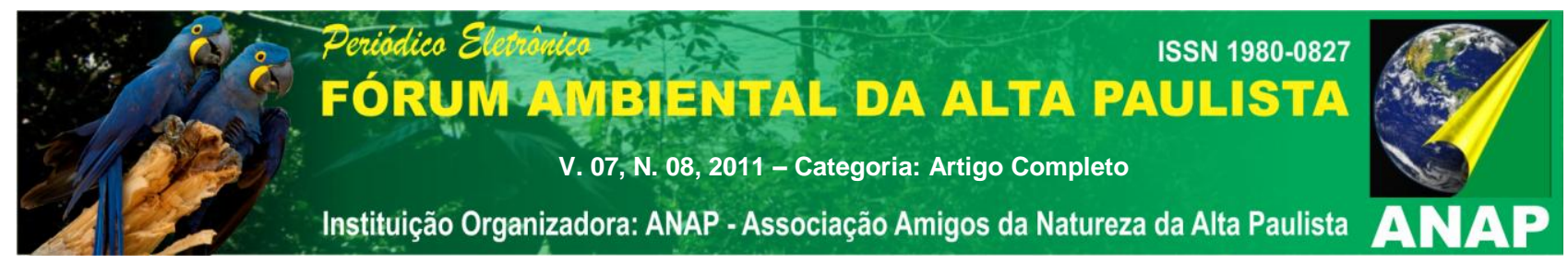

O ponto 2 (P2) é caracterizado como local com vegetação rala na margem direita do rio Miranda, é considerado um ambiente intermediário, em virtude de manter uma população vegetal bastante restrita, quando comparada com uma área de mata densa. É uma a área de campo aberto com cobertura de gramínea e não a presença de arborização significativa, o local recebe insolação direta a partir do início do dia até ao seu final (Fotos 3 e 4).

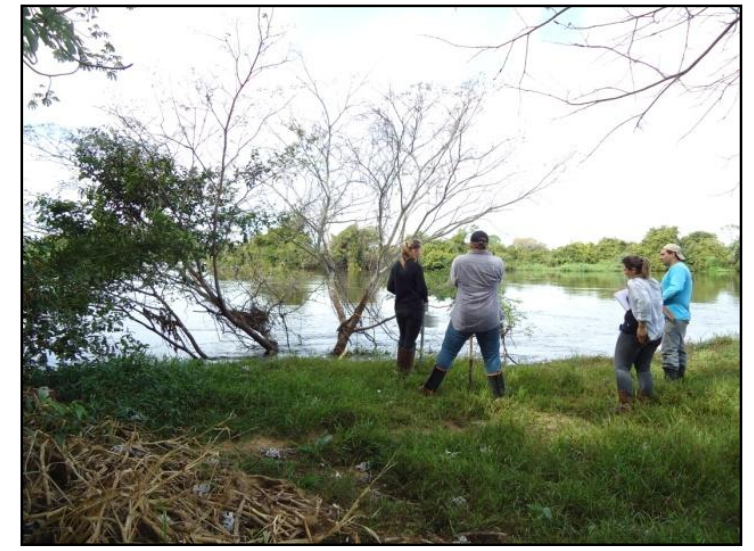

Foto 3: Margem do rio Miranda

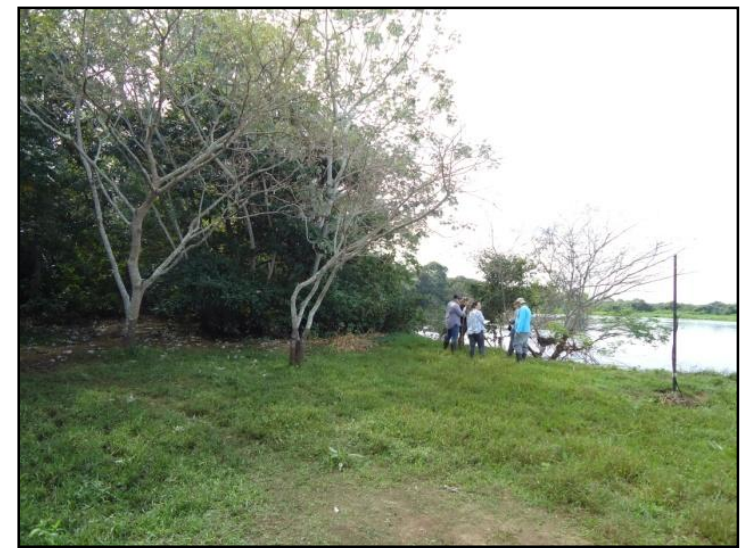

Foto 4: Vegetação intermediária

O ponto 3 (P3) é caracterizado como área construída (BEP-UFMS) é um ambiente que possui em seu entorno algumas edificações, vegetação arbórea, arbustiva e uma área rebaixada alagada. A sensação térmica do local apresentava-se mais quente em relação aos demais pontos (Fotos 5 e 6 ).

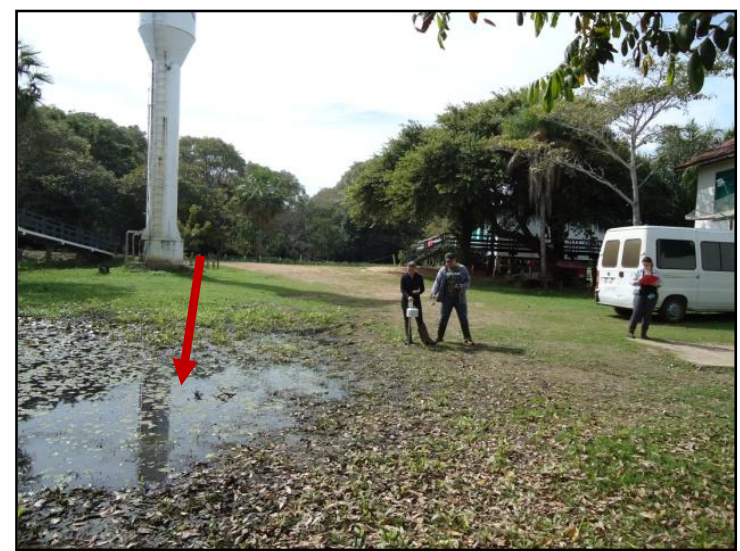

Foto 5: Área rebaixada alagada

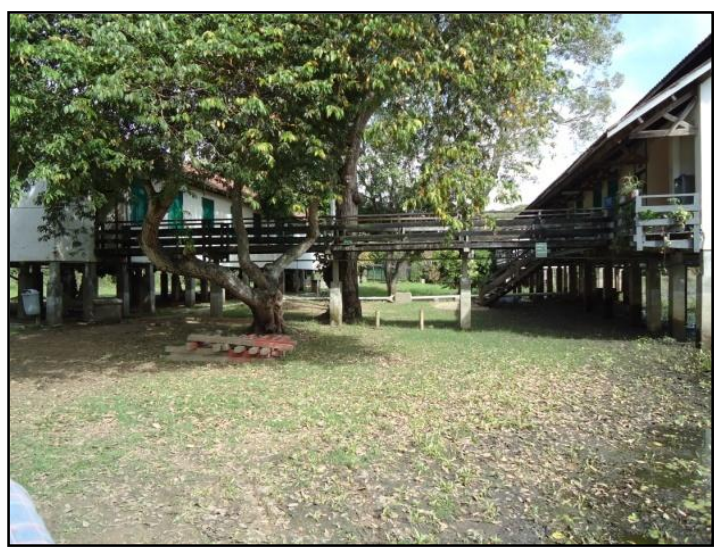

Foto 6: Instalações BEP-UFMS 


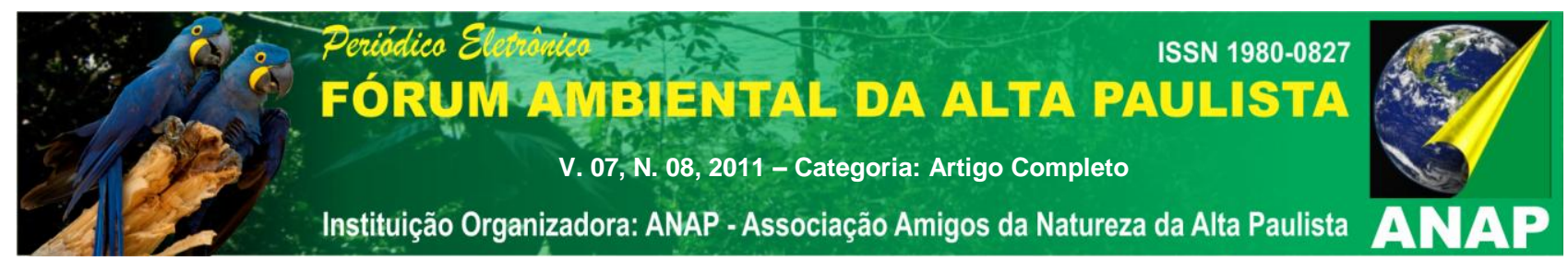

O ponto 4 (P4) é caracterizado como uma área de vegetação ao longo da estrada não pavimentada de ligação BEP-UFMS. Essa via foi construída em aterro, tornando topograficamente elevada contribuindo para o aprisionamento de água em algumas áreas nas margens desta via (Fotos 7 e 8 ).

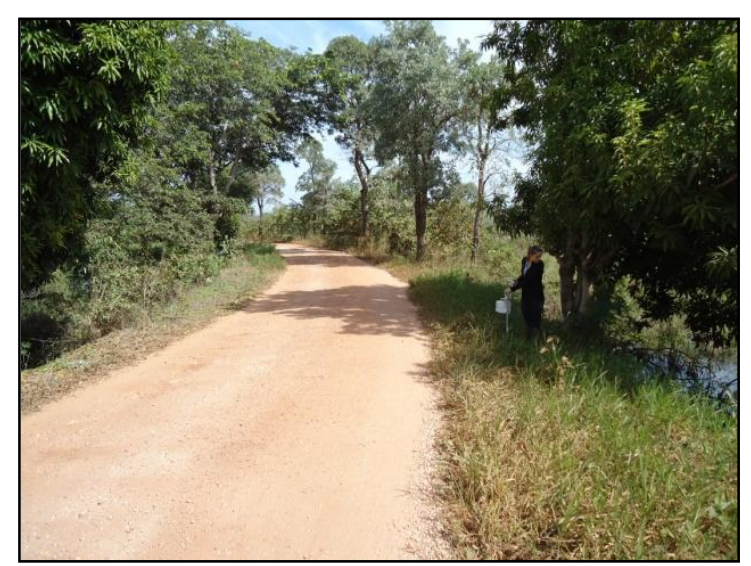

Foto 7: Estrada de ligação BEP-UFMS

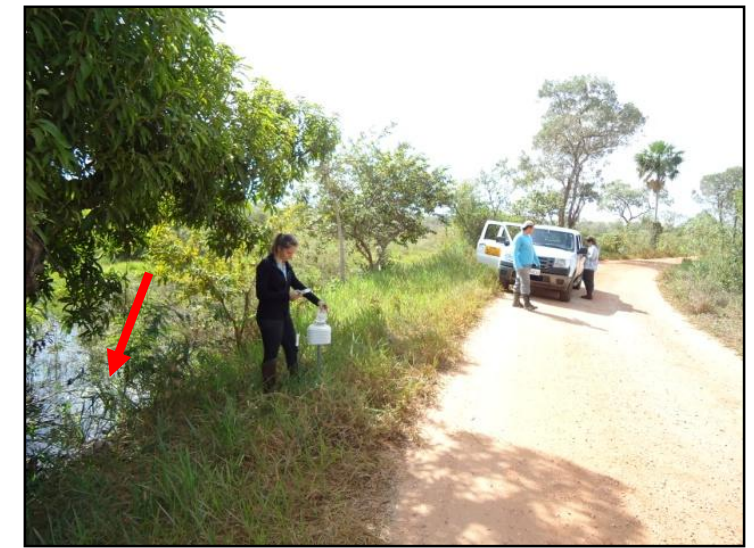

Foto 8: Aprisionamento de água

O ponto 5 (P5) é caracterizado como área construída com intervenção humana. O ambiente é totalmente aberto e ventilado com vegetação arbórea de grande e médio porte e jardim ornamental. $O$ terreno não é pavimentado, porém possui uma cobertura de cascalhos (Fotos 9 e 10).

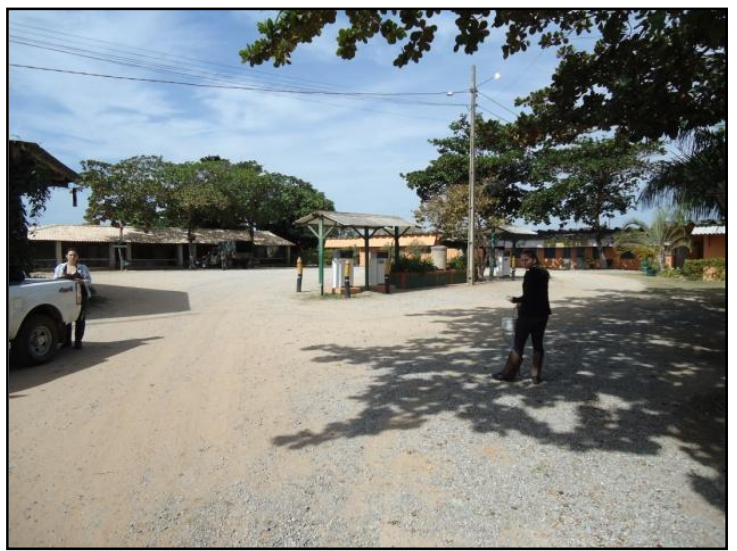

Foto 9: Área construída

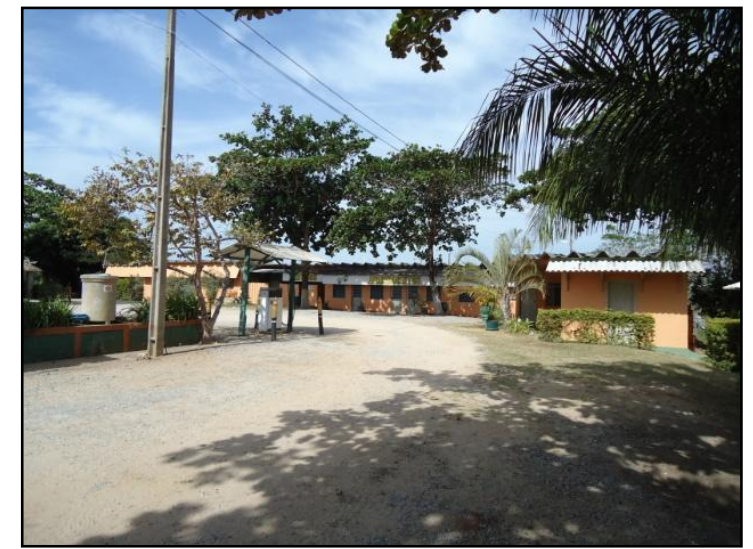

Foto 10: Terreno coberto de cascalho

O ponto 6 (P6) encontra-se próximo a margem direita do rio Miranda na comunidade ribeirinha. $\mathrm{O}$ ambiente é caracterizado como área construída com casas de madeira em terreno com áreas cimentadas de solo exposto. A presença de vegetação
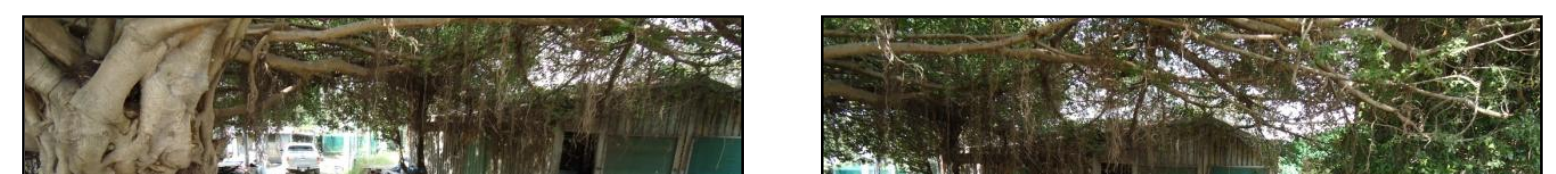


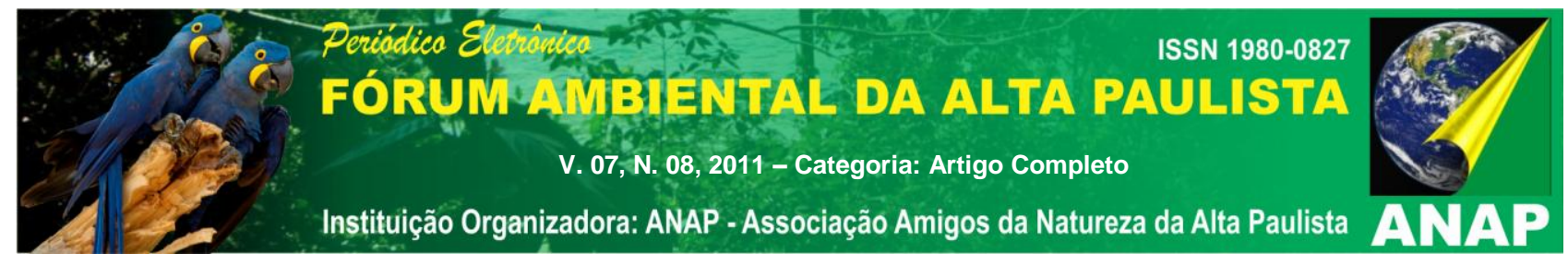

arbórea é bastante restrita, as árvores são de porte grande com as copas bem definidas, com insolação restrita na maior parte do dia (Fotos 11 e 12).

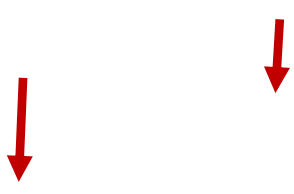

Foto 11: Áreas cimentadas e solo exposto 3.2 Análise dos registros

Foto 12: Casa de madeira

No dia 04 de junho de 2011 o tempo na região do Pantanal sul mato-grossense encontrava-se sob domínio de uma Massa Tropical (Figura 3) o que predominou céu claro e temperaturas elevadas.

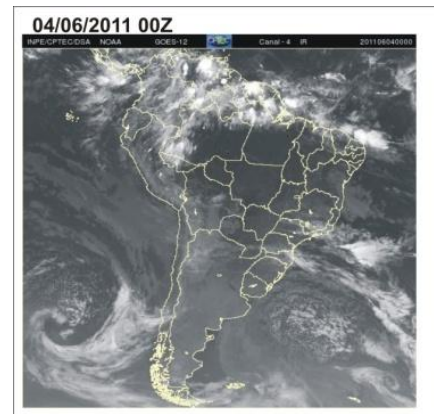

$04 / 06 / 201112 Z$
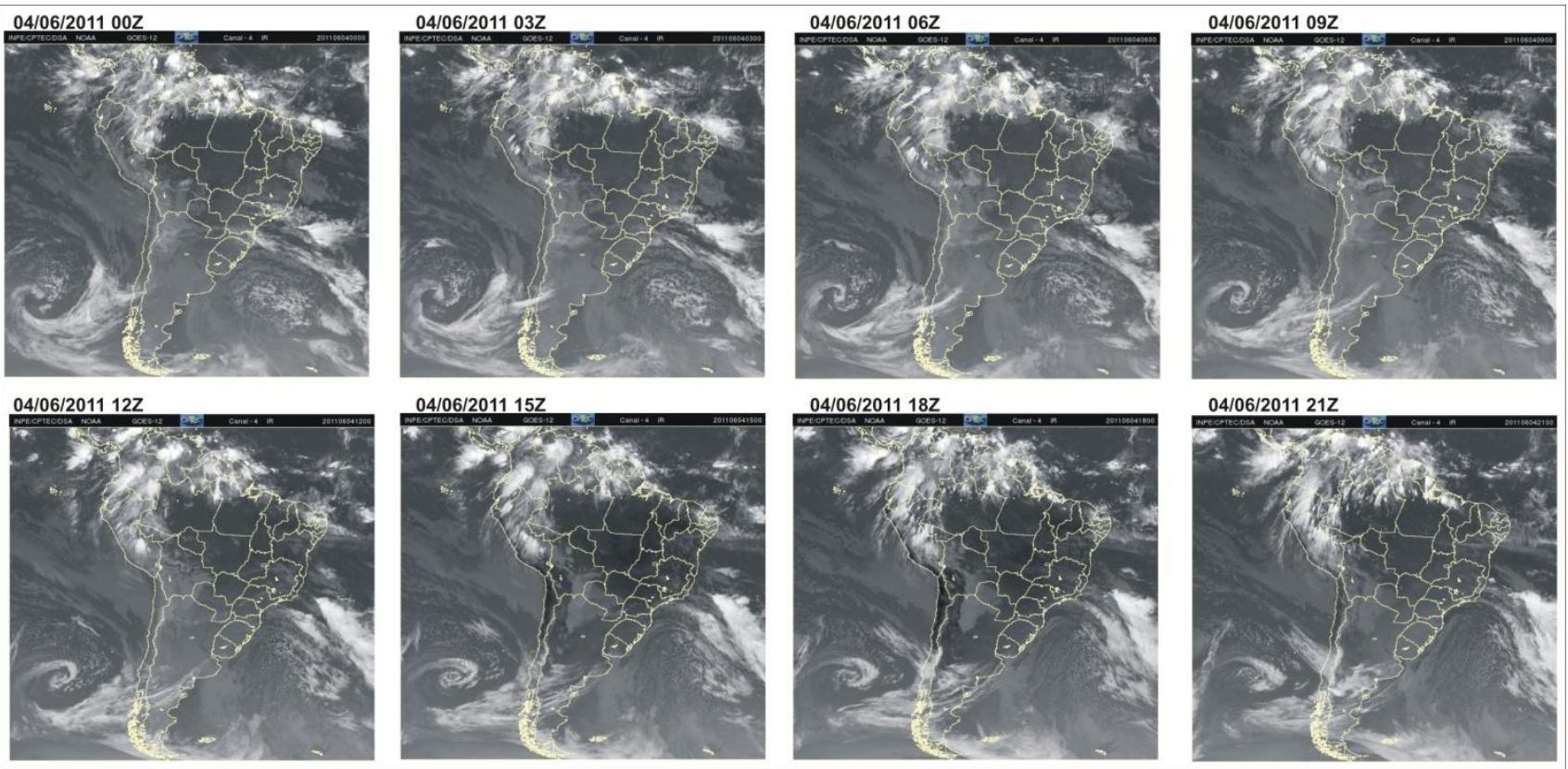

Figura 3: Imagens do satélite meteorológico Goes 12 - 04/06/2011 - 00:00Z até 21:00Z.

Org.: FERREIRA, PONSO e SOKOLOWSK.

Nos registros do transeto no intervalo dás 9h, a variação da temperatura foi de $1,5^{\circ} \mathrm{C}$, sendo que a maior temperatura registrada foi de $24,5^{\circ} \mathrm{C}$ no Ponto 4 (P4); e a menor 


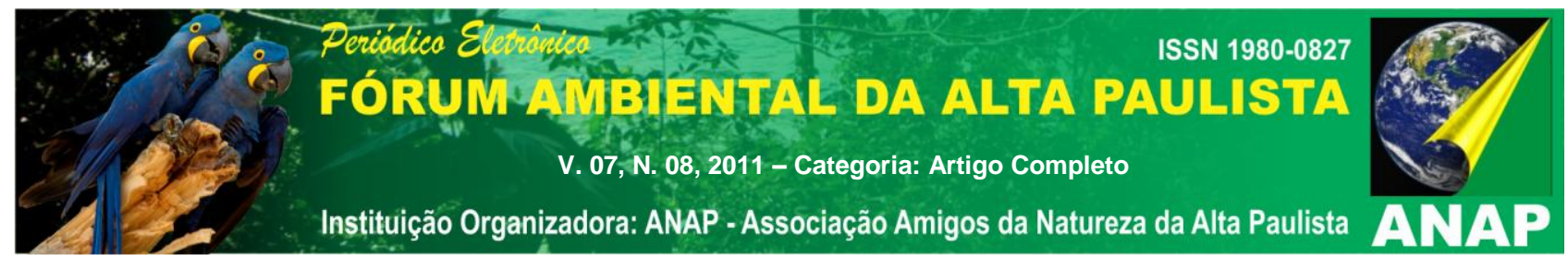

temperatura registrada foi de $23^{\circ} \mathrm{C}$ no Ponto $1(\mathrm{P} 1)$. Nos demais pontos a temperatura oscilou entre $23,2^{\circ} \mathrm{C}$ e $24,4^{\circ} \mathrm{C}$ (Tabela 1 ).

Tabela 1: Medidas de temperatura do ar em diferentes paisagens no Pantanal do Miranda transeto $1-9 \mathrm{~h}-04 / 06 / 1011$

\begin{tabular}{c|c|c|c}
\hline PONTO & LOCALIDADE & HORÁRIO & TEMPERATURA \\
\hline 01 & Mata (Lagoa da Medalha) & $8 \mathrm{~h} 53 \mathrm{~min}$ & $23^{\circ} \mathrm{C}$ \\
\hline 02 & Saída da mata, próximo ao rio & $9 \mathrm{~h} 13 \mathrm{~min}$ & $23,2^{\circ} \mathrm{C}$ \\
\hline 03 & Área construída da BEP & $9 \mathrm{~h} 20 \mathrm{~min}$ & $23,9^{\circ} \mathrm{C}$ \\
\hline 04 & Estrada de ligação a BEP & $9 \mathrm{~h} 28 \mathrm{~min}$ & $24,5^{\circ} \mathrm{C}$ \\
\hline 05 & Pousada Passo do Lontra & $9 \mathrm{~h} 36 \mathrm{~min}$ & $24,3^{\circ} \mathrm{C}$ \\
\hline 06 & População ribeirinha Passo do & $9 \mathrm{~h} 44 \mathrm{~min}$ & $24,4^{\circ} \mathrm{C}$ \\
\hline
\end{tabular}

Org.: PONSO e SOKOLOWSKI.

Nos registros do transeto no intervalo das $15 \mathrm{~h}$, a variação da temperatura do ar foi de $1,8^{\circ} \mathrm{C}$. A maior temperatura registrada nesse período foi no Ponto 4 (P4) com 27,6ํㅡ; e a menor temperatura registrada foi no Ponto $1(\mathrm{P} 1)$ com $25,8^{\circ} \mathrm{C}$. Nos demais pontos a temperatura variou entre $26,4^{\circ} \mathrm{C}$ e $27,4^{\circ} \mathrm{C}$ (Tabela 2 ).

Tabela 2: Medidas de temperatura do ar em diferentes unidades de paisagem no Pantanal do Miranda - transeto $2-15 \mathrm{~h}-04 / 06 / 1011$

\begin{tabular}{c|c|c|c}
\hline PONTO & LOCALIDADE & HORÁRIO & TEMPERATURA \\
\hline 01 & Mata (Lagoa da Medalha) & $15 \mathrm{~h}$ & $25,8^{\circ} \mathrm{C}$ \\
\hline 02 & $\begin{array}{c}\text { Saída da mata, próximo ao rio } \\
\text { Miranda }\end{array}$ & $15 \mathrm{~h} 15 \mathrm{~min}$ & $26,4^{\circ} \mathrm{C}$ \\
\hline 03 & Área construída da BEP & $15 \mathrm{~h} 29 \mathrm{~min}$ & $26,5^{\circ} \mathrm{C}$ \\
\hline 04 & Estrada de ligação a BEP & $15 \mathrm{~h} 40 \mathrm{~min}$ & $27,6^{\circ} \mathrm{C}$ \\
\hline 05 & Pousada Passo do Lontra & $15 \mathrm{~h} 53 \mathrm{~min}$ & $27,4^{\circ} \mathrm{C}$ \\
\hline 06 & População ribeirinha Passo do & $16 \mathrm{~h}$ & $27,2^{\circ} \mathrm{C}$ \\
\hline
\end{tabular}

Org.: PONSO e SOKOLOWSKI. 


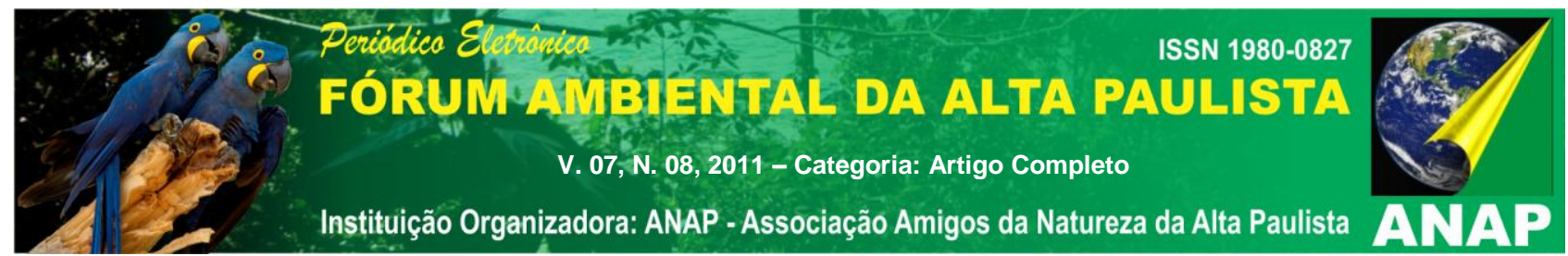

Nos registros do transeto no intervalo das $21 \mathrm{~h}$, a variação da temperatura foi de 0,5ㄷ․ Segundo os dados registrados o Ponto (P1) obteve-se maior temperatura com registro de $22,2^{\circ} \mathrm{C}$, e a menor temperatura registrada foi de $21,5^{\circ} \mathrm{C}$ no Ponto 4 (P4). Nos demais pontos a temperatura permaneceu $21,8^{\circ} \mathrm{C}$, não obtendo nenhuma alteração (Tabela 3).

Tabela 3: Medidas de temperatura do ar em diferentes unidades de paisagem no Pantanal do Miranda - transeto $3-21 \mathrm{~h}-04 / 06 / 1011$

\begin{tabular}{c|c|c|c}
\hline PONTO & LOCALIDADE & HORÁRIO & TEMPERATURA \\
\hline 01 & Mata (Lagoa da Medalha) & $21 \mathrm{~h} \mathrm{04min}$ & $22,2^{\circ} \mathrm{C}$ \\
\hline 02 & $\begin{array}{c}\text { Saída da mata, próximo ao rio } \\
\text { Miranda }\end{array}$ & $21 \mathrm{~h} 20 \mathrm{~min}$ & $21,8^{\circ} \mathrm{C}$ \\
\hline 03 & Área construída da BEP & $21 \mathrm{~h} 30 \mathrm{~min}$ & $21,8^{\circ} \mathrm{C}$ \\
\hline 04 & Estrada de ligação a BEP & $21 \mathrm{~h} 43 \mathrm{~min}$ & $21,5^{\circ} \mathrm{C}$ \\
\hline 05 & Pousada Passo do Lontra & $21 \mathrm{~h} 50 \mathrm{~min}$ & $21,8^{\circ} \mathrm{C}$ \\
\hline 06 & $\begin{array}{c}\text { População ribeirinha Passo do } \\
\text { Lontra }\end{array}$ & $22 \mathrm{~h}$ & $21,8^{\circ} \mathrm{C}$ \\
\hline
\end{tabular}

Org.: PONSO e SOKOLOWSKI.

\subsection{Discussão dos resultados}

Podemos considerar a vegetação, água e a ocupação do solo da área estudada como um fator de relevância no microclima local.

De acordo com Florenzano (2011), a interação da energia com os objetos da superfície terrestre como água, vegetação e solo, refletem, absorvem e transmitem radiação eletromagnética em proporções que variam com o comprimento de onda, de acordo com suas características biofísicas e químicas.

Nos registros do transeto no intervalo das (9h) e das (15h) apresentaram mesmas evidencias com o ponto 4 (P4), apresentando as maiores temperaturas, tendo em vista a influencia do horário de medida e dos intervalos, além disso o local estava sob predomínio de céu claro e a intensidade do vento ficou entre 2 e 3 na escala de BEUAFORT. 


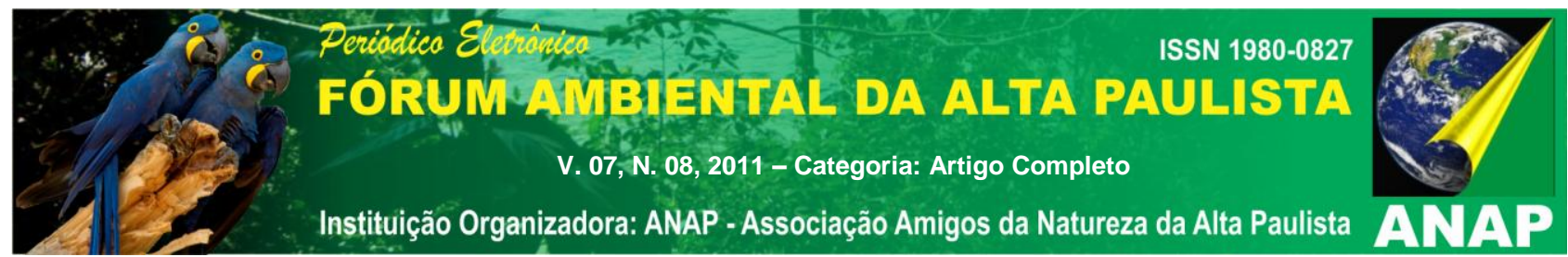

As menores temperaturas medidas foi no ponto 1 (P1), mata (próximo a Lagoa da Medalha) foram influenciadas pela alta umidade do local, devido a arborização densa e sombreamento da área e pela proximidade do rio Miranda e da Lagoa da Medalha. Nos registros do transeto no intervalo das (9h e 15h) a intensidade do vento ficou entre 1 e 2 , baseado na escala de BEUAFORT.

No registro do transeto, no intervalo das $21 \mathrm{~h}$ houve uma inversão das temperaturas, a maior temperatura registrada foi no ponto 1 (P1) (mata próximo a Lagoa da Medalha), acredita-se que esse registro se deve a arborização densa e sombreamento da área durante o dia, na mata. Nesse período a área encontrava-se abafada e com umidade relativa alta devido à densa arborização, o que deixou a temperatura do local mais alta em relação aos demais pontos.

A menor temperatura, no registro do transeto, no intervalo das (21h) foi no ponto 4 (P4), a área é ampla e aberta com muita iluminação durante o dia, a noite ao contrario, contribuiu para a temperatura se apresentar mais baixa, a intensidade do vento nesse ponto foi de 3 na escala de BEUAFORT, o que favoreceu a uma temperatura mais baixa. Os demais pontos tiveram as mesmas temperaturas.

Nas três medidas do transeto, as temperaturas intermediárias foram nos mesmos pontos (2, 3, 5 e 6$)$ as mesmas apresentaram características semelhantes tais como, área construída, arborização, gramínea e solo exposto. (Figura 4). 

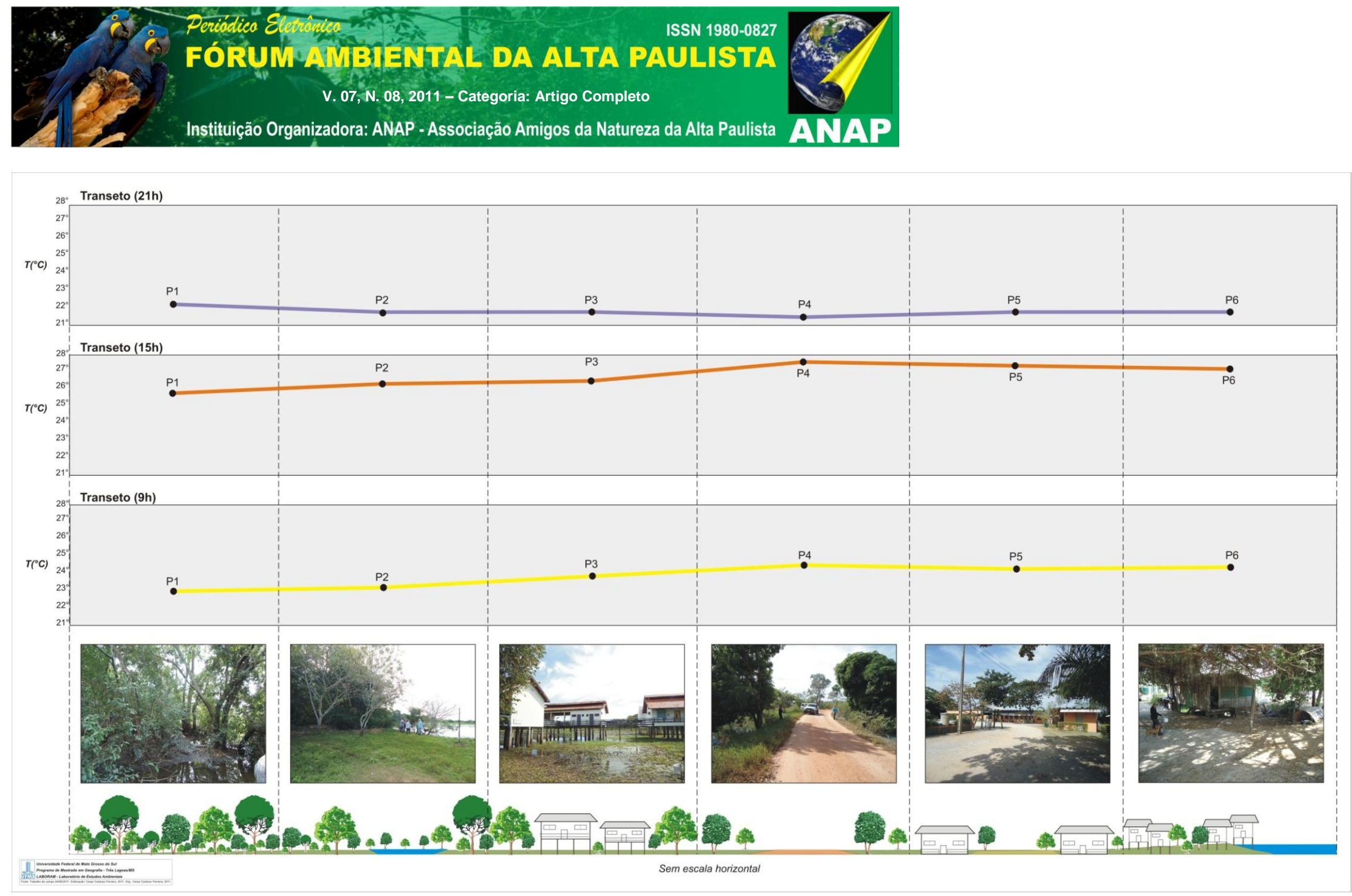


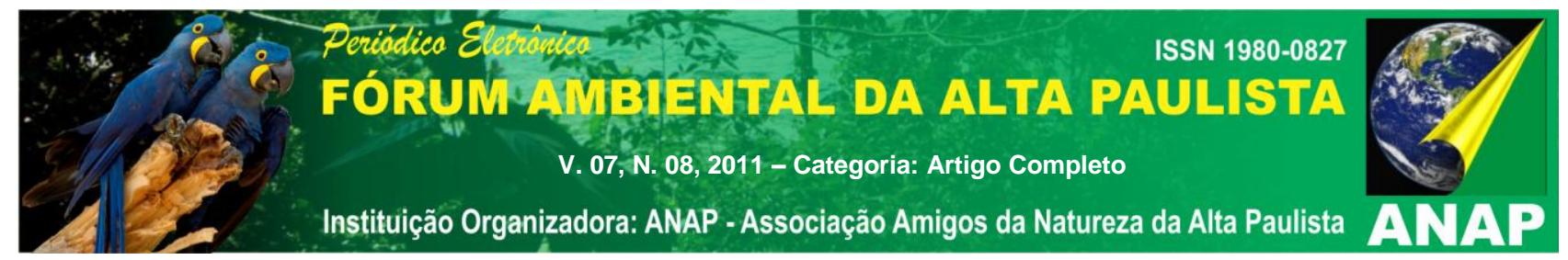

Figura 4: Croqui das unidades das paisagens do transeto e gráficos das temperaturas medidas nos diferentes intervalos e períodos. Org.: FERREIRA. 


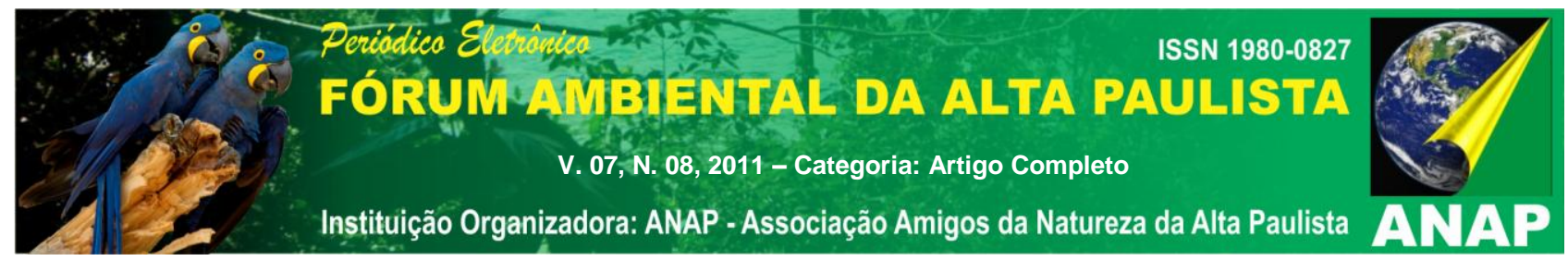

\section{CONSIDERAÇÕES FINAIS}

Em relação aos métodos e procedimentos utilizados, revelou sua eficácia para a coleta de dados e posteriormente análise dos mesmos transformando-os em informações microclimáticas das áreas estudadas. Este estudo revelou a ocorrência das variações microclimáticas no Passo do Lontra no Pantanal do Miranda, considerando as diferentes unidades de paisagem e os períodos do dia. Nas três medidas do transeto, as temperaturas intermediárias foram nos mesmos pontos (2, 3, 5 e 6) as mesmas apresentaram características semelhantes tais como, área construída, arborização, gramínea e solo exposto. Nos pontos 1 e 4 as diferenças de temperatura foram mais acentuadas, combinadas com arborização densa no ponto 1 e solo exposto no ponto 4 .

Os estudos realizados mostraram a importância de se classificar e coletar dados em transeção, associados a uso e ocupação do solo, desde modo, nos permite concluir que o uso e ocupação têm interferência na variação climática dos ambientes.

\section{BIBLIOGRAFIA}

ALVARENGA, Silvia Maria; BRASIL, Antonia Eloísa; DEL'ARCO, Diana Melo. Geomorfologia. In. Projeto RADAMBRASIL. Levantamento de recursos naturais. Folha SF 21 Campo Grande: Rio de Janeiro, 1982.

BERTRAND, G. Paisagem e Geografia Física Global: Esboço metodológico. Caderno de Ciências da Terra, 13. Inst. de Geografia-USP. São Paulo. 1971.

FLORENZANO, T.G. Iniciação em sensoriamento remoto. $3^{\text {a }}$ Ed de imagens de satélite para estudos ambientais. São Paulo: Oficina de Textos, 2011.

GODOI FILHO, J. D., Aspectos Geológicos do Pantanal Mato-grossense e sua Área de Influência. In: Simpósio Sobre Recursos Naturais e Sócio-Econômico do Pantanal, 1. 1986, Corumbá - MS. Anais... Brasília - DF. EMBRAPA/CPAP, 1986. p 63-77.

GRADELLA, Frederico dos Santos. Comportamento térmico em unidades da Paisagem no Pantanal da Nhecolândia/MS-Brasil: estudo de caso na Fazenda Nhumirim/EMBRAPA/Pantanal. UFMS: Três Lagoas, 2005.

GRADELLA, dos S. F. Aspectos da Dinâmica Hidroclimática da Lagoa Salina do Meio na Fazenda Nhumirim e seu entorno, Pantanal da Nhecolândia, MS - Brasil. Dissertação (mestrado), UFMS/CPAQ, Aquidauana, 2008. 


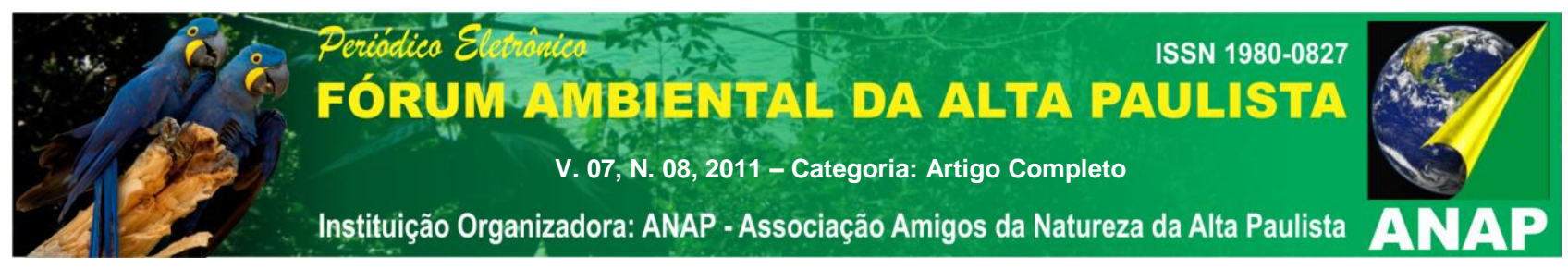

REZENDE FILHO, A. T. Variabilidade de salinidade de uma área em uma baía/vazante na Fazenda Nhumirim, Pantanal da Nhecolândia: estudo de um método cartográfico. (Especialização). UFMS/CPTL, Três Lagoas, 2003

SAKAMOTO, Arnaldo Yoso; QUEIROZ NETO, José Pereira de; FERNANDES, Ermínio; LUCATTI, Hebert M. Topografia de lagoas salinas e seus entorno no Pantanal da Nhecolândia/MS. In: Resumos do II Simpósio Sobre Recursos Naturais e Sócio Econômicos do Pantanal: Manejo e Conservação. EMBRAPA/CPAP-UFMS: Corumbá, 1996.

SILVA, J.S.V. \& ABDON, M.M. 1998. Delimitação do Pantanal Brasileiro e suas subregiões. Pesquisa Agropecuária Brasileira 33:1703-1711

SILVA, Lenise Robles Borba. Microclima no Pantanal Sul-mato-grossense: análise do campo térmico em unidades da Paisagem da Nhecolândia (monografia de graduação). UFMS/CPTL. Três Lagoas, 2003.

SILVA, M. H. S, Subsídios para a compreensão dos processos pedogenéticos da lagoa Salitrada: Pantanal da Nhecolândia, MS. Dissertação (mestrado), UFMS/CPAQ, Aquidauana, 2007. 